\title{
Changes to mental illness handbook not taken lightly
}

Previously published at www.cmaj.ca

$\mathrm{F}$ rom its humble beginnings in 1952, the Diagnostic and Statistical Manual of Mental Disorders continues to grow, both in thickness and influence. Published by the American Psychiatric Association, the DSM, as it is commonly known, is a field guide to the broad and ambiguous world of mental disorders. It is also, according to some critics, a book that turns everything from shyness to adolescence into a disease. Despite such criticisms, the manual is still used extensively by mental health researchers and practitioners all over the world.

"It is an extremely important document because it provides a classification and nomenclature for mental disorders," says Dr. Stanley Yaren, president of the Canadian Psychiatric Association. "Before the DSM, you had clinicians and researchers speaking different languages."

The DSM was originally intended merely to provide statistical information about mental disorders - 106 of which were listed in its first edition, DSM-I. The current version, DSM-IV, was published in 1994 and contains nearly 300 disorders - everything from social phobia (shyness, in other words) to frotteurism (an irresistable urge to sexually touch fellow passengers on mass transit). The next edition, $D S M-V$, is expected to be published in May 2012. Over time, the manual has come to be used by researchers, clinicians, insurers, pharmaceutical companies, policy-makers, lawyers - any party that stands to benefit, somehow, by having a particular set of symptoms or behaviours labelled as diagnostic criteria for a mental disorder. That's not to say that all the people who consult the DSM are using it properly.

"The DSM should only be used by trained professionals who know how to take the clinical situation in the proper context," says Yaren. "There is a great deal of wiggle room in many entries."

Participants in the DSM revision

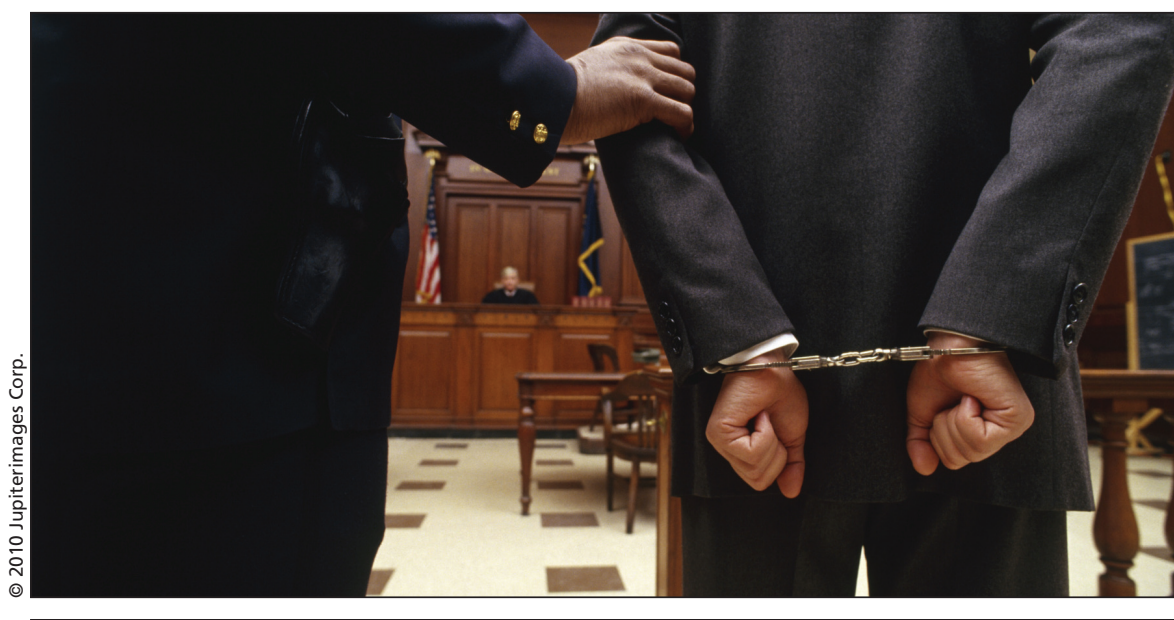

Slight changes to the wording in the Diagnostic and Statistical Manual of Mental Disorders can have significant consequences, including blurring the line, in courts of law, between mental disorders and ordinary criminality, former DSM editors Dr. Michael First and Dr. Allen Frances say.

process are aware of the pitfalls of defining mental illnesses in definite terms. In the Canadian Journal of Psychiatry, a contributor to DSM-IV wrote that a user-friendly and broadly accepted system such as the DSM "will bind many uncritical practitioners to it, errors and all. On the other hand, the very act of describing a diagnosis in unambiguous and replicable terms will create and give direction to a corrective process" (Can J Psych 1996;41:325-9).

In 1997, a more cynical assessment of the $D S M$ 's value appeared in Harper's Magazine, which called $D S M-I V$ a handbook that "lists a madness for everyone" (www.harpers.org /archive/1997/02/0008270). The author, L.J. Davis, argued that the diagnostic criteria in the manual are based on pseudo-science and that many psychiatric disorders do not exist, while others are merely symptoms of physical diseases: "We are confronted with a world view where everything is a symptom and the predominant color is a shade of therapeutic grey. This has the advantage of making the therapist's job both remarkably simple and remarkably lucrative."
Though people disagree about the value of the $D S M$, there is little doubt that adding a new disorder to it or changing one of its entries can have significant consequences. Sometimes the consequence is positive. An overlooked disorder, for example, could receive greater attention, spurring increased funding for research and treatment development.

A new entry can also benefit patients by legitimizing their problems. In the United States, it also means a new DSM code that patients can use to recover the cost of treatment from health insurers. (DSM codes are irrelevant to Canadian physicians but are used sometimes to measure severity of disorders in cases of disability insurance and by psychologists and therapists who bill through private insurance plans.) But sometimes a change to the manual, even a slight change, has an unintended negative consequence.

In a 2008 editorial, two former DSM editors (Dr. Michael First and Dr. Allen Frances) wrote that a slight wording change to one section had resulted in some criminal lawyers coming to the conclusion that sexual offenders could be labelled as mentally ill based on their actions alone, which "blurs the distinc- 
tion between mental disorder and ordinary criminality" (Am J Psych 2008; 165:1240-1). They concluded that "tinkering with criteria wording should be done only with great care and when the
The DSM revision process is conducted by a designated task force, which establishes working groups to focus on specific diagnostic areas. The process changes with each new edition,

\section{'When things get in the DSM, it's very hard to get them out. It's like a black hole." - Dr. Michael First, editor of text and criteria for DSM-IV.}

advantages clearly outweigh the risks, both because of the potentially unforeseen consequences of rewording criteria and because of the disruptive nature of all changes."

Because the stakes are high, changes to the DSM are not taken lightly. Though there are no restrictions on who is allowed to propose a disorder to be added to the DSM, unless a proposal is accompanied by a substantial body of sound scientific data, it stands little chance of success.

"If everybody got their pet condition entered, the DSM would no longer be very useful," says Yaren. "It would just be a collection of ideas and theories rather than an attempt to have a validated classification of mental disorders." but generally adheres to the same pattern: review, consultation, testing.

An extensive literature review is conducted on the problematic areas of the current edition. Working groups analyze the scientific data and draft initial proposals of possible additions and changes. Other experts are then asked to review these proposals and provide feedback. Then field trials are conducted in mental health facilities and primary care settings to test the feasibility and clinical utility of the proposed revisions. The results shape the working groups final recommendations, which go the American Psychiatric Association for approval.

The biggest change to the DSM-V revision process - according to Dr. William Narrow, research director of the
$D S M-V$ task force - is a new focus on "dimensional assessments," intended to make diagnoses of mental disorders a matter of degree, rather than just a yes or no assessment. "This will hopefully add to the usability of the DSM in terms of getting away from the strict categorical direction that the DSM has been going in and allow practitioners to actually document in a more quantitative way the comorbidities and the grey areas of their patients' disorders," says Narrow.

A shortcoming of the DSM revision process is that the risk of overdiagnosis is usually not taken into consideration by people making proposals for new disorders, says Dr. Michael First, who served as editor of text and criteria for $D S M-I V$. Advocates for adding a particular disorder tend to focus too much on cases they believe are being missed, he says, and too little on the potential of a new entry to create many false positives. The potential good of adding a new disorder to the DSM should outweigh the potential harm, says First, because when a disorder gains entry it tends to remain in the manual's pages for a long time.

"When things get in the DSM, it's very hard to get them out," says First. "It's like a black hole." - Roger Collier, CMAJ

DOI:10.1503/cmaj.109-3105

\section{DSM revision surrounded by controversy}

Previously published at www.cmaj.ca

$\mathrm{F}$ ormer editors of the Diagnostic and Statistical Manual of Mental Disorders (DSM) have publicly declared their concerns that the ongoing revision process of the influential publication has been cloaked in secrecy. In recent months, debate about the confidentiality agreement that contributors must now sign has been playing out in the pages of the Psychiatric Times. Dr. Allen Frances, editor of DSM-IV, has written several editorials slamming the $D S M-V$ task force for their lack of transparency.

The "real problem now is the almost complete lack of openness about [DSM$V]$ methods, progress, timelines, and products," Frances writes in an email.
Dr. Robert Spitzer, editor of DSMIII, has expressed a similar opinion. In 2008, he wrote an open letter criticizing the confidentiality agreement (Psychiatr News 2008; 43:26). In the letter, Spitzer says that he requested the minutes of a $D S M-V$ meeting but was refused. The confidentiality mandate, he wrote, would prohibit the free exchange of information between the DSM task force and outside experts that is essential to effectively revising the manual.

Members of the American Psychiatric Association, which publishes the $D S M$, have countered these criticisms by claiming the revision process has never been more open. There are more than 150 experts from 16 countries contributing to the manual, the association has noted, and the confidentiality agreement serves primarily to protect intellectual property and to allow task force members to provide input on certain matters without fear of outsiders misinterpreting it or coming to premature conclusions.

"With each version of the DSM that comes out, there is more and more openness in terms of transparency and in terms of making sure that interested parties are kept updated as well as possible," says Dr. William Narrow, director of the DSM-V task force. "But there is a delicate balance between being totally transparent versus allowing a scientific process to take place."

The debate between the former and current editors has taken a turn toward the personal of late. In a response to 